\title{
Impact of plantar fasciitis on the quality of life of male and female patients according to the Foot Health Status Questionnaire
}

This article was published in the following Dove Press journal: Journal of Pain Research

\author{
Patricia Palomo-López \\ Ricardo \\ Becerro-de-Bengoa-Vallejo ${ }^{2}$ \\ Marta Elena Losa-Iglesias ${ }^{3}$ \\ David Rodríguez-Sanz ${ }^{4}$ \\ César Calvo-Lobo ${ }^{5}$ \\ Daniel López-López ${ }^{6}$
}

'Department of Nursing, University Center of Plasencia, Universidad de Extremadura, Spain; ${ }^{2}$ School of Nursing, Physiotherapy and Podiatry, Universidad Complutense de Madrid, Spain; ${ }^{3}$ Faculty of Health Sciences, Universidad Rey Juan Carlos, Spain; ${ }^{4}$ Physiotherapy Department, Faculty of Health, Exercise and Sport, European University of Madrid,Villaviciosa de Odón, Madrid, Spain; ${ }^{5}$ Nursing and Physical Therapy Department, Faculty of Health Sciences, University of León, Ponferrada, León, Spain; ${ }^{6}$ Research, Health and Podiatry Unit, Department of Health Sciences, Faculty of Nursing and Podiatry, Universidade da Coruña, Spain
Correspondence: César Calvo-Lobo Nursing and Physical Therapy Department, Institute of Biomedicine (IBIOMED), Faculty of Health Sciences, University of León, Av Astorga, s/n, 2440I Ponferrada, León, Spain Email ccall@unileon.es
Background and purpose: Plantar fasciitis (PF) is a foot disorder in adults secondary to an inflammatory response caused by repetitive micro-trauma. We evaluated and compared the impact on quality of life (QoL) related to foot health and general health between males and females with PF.

Methods: In this cross-sectional descriptive study, patients with PF were recruited from a podiatry clinic. Physical examination, sociodemographic data, and the self-reported Foot Health Status Questionnaire (FHSQ) were recorded. The FHSQ has three sections and provides two composite scores from 0 to 100 . Higher scores (close to 100) reflect better QoL related to foot health and health in general; lower scores (close to 0 ) denote a worse QoL related to these health items.

Results: One hundred patients (49 males [42.38 \pm 14.065 years old] and 51 females [43.90 \pm 14.305 years old]) were recruited. Section one of the FHSQ evaluates four foot domains, and significant differences $(P<0.05)$ were shown for foot pain and footwear, with males having higher scores than females, but not for foot function and general foot health $(P>0.05)$. Section two assesses four domains of general wellbeing, and significant differences $(P<0.05)$ were shown for overall health, physical function, social capacity, and vigor, with males having higher scores than females.

Conclusion: Females with PF showed a worse health-related QoL for foot pain, foot function, footwear, and general foot health than males. A better health-related QoL was also shown for males with PF than for females with regard to general health, physical activity, social capacity, and vigor. Keywords: plantar fasciitis, foot health status, foot pain, quality of life

\section{Introduction}

Plantar fasciitis (PF; also known as "plantar heel pain") is a common foot disorder in adults secondary to an inflammatory response caused by repetitive micro-trauma. PF is commonly observed by health care practitioners, and is a musculoskeletal disease. ${ }^{1}$ Typically, this pain is described as "burning", "aching" and, occasionally, "lancinating". PF may increase during the first steps after waking-up or a prolonged rest. ${ }^{2}$ Furthermore, this pain can be associated with tenderness at the medial calcaneal tuberosity and along the plantar fascia. ${ }^{3}$

PF may affect $>1$ million people worldwide per year. ${ }^{4,5}$ The exact prevalence of PF is not known. The lifetime prevalence may reach $10 \%$ of the general population worldwide., ${ }^{4,6}$ A local population study of 3206 participants in Australia showed that the prevalence of heel pain was 3.6\%. ${ }^{7}$ Landorf reported that the prevalence and prognosis of PF are not clear, though the symptoms seem to resolve over time in most people. ${ }^{8}$ Approximately $11 \%-15 \%$ of all foot symptoms require long-term professional care and affect all age 
groups, sexes, and ethnicities, with a higher prevalence noted in females aged $40-60$ years. $^{9}$

Terms such as "jogger's heel", "tennis heel" or "policeman's heel" have been used to describe PF. Indeed, the most common etiologies of heel pain are mechanical factors. Common causes of heel pain include heel spur, Sever's disease, heel bump, Achilles tendinopathy, heel neuritis, and heel bursitis. ${ }^{10}$ After the initial inflammatory response and repetitive micro-trauma of plantar aponeurosis, myxoid degeneration with PF fragmentation as well as vascular ectasia in bone marrow, are the most common histologic findings. Therefore, PF may be considered a degenerative fasciosis in the absence of inflammation. ${ }^{11}$

Pain and tenderness are sometimes extended into the medial arch. Pain associated with this condition may cause substantial disability and poor health-related quality of life (QoL). Risk factors include obesity, occupations that necessitate prolonged standing, pes planus, limited ankle dorsiflexion, plantar heel spurs and running, ${ }^{7}$ sedentary or athletic occupations, excessive foot pronation, and excessive running. ${ }^{5}$

Furthermore, $\mathrm{PF}$ is associated with significant gait-related disability. Specific deviations of the foot and ankle gait in individuals with PF compared with asymptomatic controls have been reported. ${ }^{12}$ Chronic PF shows a poorer foot-specific and general health-related QoL with respect to healthy matched controls, without being associated with age, sex, or the body mass index (BMI). "Foot health" may be defined as physical, social, and psychologic wellbeing related specifically to the foot. Foot health can be measured by means of the Foot Health Status Questionnaire (FHSQ). In addition, the FHSQ can be used to assess the general health-related QoL. ${ }^{2,13}$ Nevertheless, the effects of PF on QoL related to foot health and general health in patients with this disorder according to sex differences between females and males are not clear.

Based on these antecedents, we hypothesized that PF leads to a worse health-related QoL, which may be influenced by the sex of patients who suffer from it. Therefore, we analyzed and compared the impact on QoL related to foot health and general health between males and females with PF.

\section{Patients and methods}

\section{Ethical approval of the study protocol}

The research protocol was approved $(85 / 2016)$ by the Bioethics and Biosafety Committee at the University of Extremadura (Plasencia, Spain). The ethical standards in human experimentation contained in the World Medical Association Declaration of Helsinki, Council of Europe Convention on Human Rights and Biomedicine, UNESCO
Universal Declaration on the Human Genome and Human Rights, and those of the relevant national bodies and institutions were observed at all times. All participants provided written informed consent before being enrolled.

\section{Design and sample}

A cross-sectional, descriptive observational study was carried out following the "Strengthening the Reporting of Observational Studies in Epidemiology" statement and checklist. ${ }^{14}$ Before beginning treatment, 100 patients were recruited and examined face-to-face in the first consultation from a clinic of podiatric medicine and surgery that provides treatment for diseases/disorders of the foot at the University of Extremadura between September 2016 and January 2017. A non-randomized and consecutive sampling method was used to select these 100 participants who were enrolled in the study according to sample-size calculation.

Inclusion criteria were males or females aged 18-65 years, with PF or heel pain in the acute phase, after being diagnosed by a podiatrist, and who had not undergone treatment previously. For the diagnosis of painful heel syndrome by clinical examination, the following positive clinical signs were necessary: i) pain in the morning or after sitting down for a long time, ii) local pain where the fascia attaches to the heel, iii) increasing pain with extended walking or standing for $>15 \mathrm{~min}$. Moreover, written informed consent was mandatory. ${ }^{2,15}$

Exclusion criteria were: age $<18$ years or $>65$ years; plantar heel spurs (diagnosed by ultrasonography or prior radiographic evidence); ${ }^{16}$ previous foot trauma; dysfunction of the foot or ankle (e.g., instability); arthrosis or arthritis of the foot; surgery or previous treatment of the foot; neurologic abnormality (e.g., tarsal tunnel syndrome); non- or semi-autonomous in daily activities; inability to understand instructions.

\section{Procedure}

All participants were evaluated by means of accessing their medical record and physical examination, including ultrasonography (Mindray Z6; Shenzhen MindrayBio-Medical Electronics, Nansham, China) assessment with a 5 to $10 \mathrm{MHz}$ range linear transducer (7 L4P type; $38 \mathrm{~mm}$ footprint), ${ }^{16}$ by the same assessor in order to check the inclusion and exclusion criteria. Each participant was examined by this single trained examiner who measured height and weight so that the BMI could be calculated. ${ }^{17}$ All participants were asked to complete the self-report Spanish FHSQ.${ }^{13,20}$ This validated questionnaire on health-related QoL is intended specifically 
for the foot. ${ }^{18}$ The FHSQ has three sections and provides two composite scores from 0 to 100 . Higher scores (close to 100) reflect a better QoL related to foot health and health in general. Lower scores (close to 0 ) denote a worse QoL related to these health items. Several answers and a Likert-type ordinal scale are provided for each question. These answers varied for each domain, and only one item was selected to be the most appropriate response. The questionnaire does not show a global score but rather provides an index for each specific domain. In order to get these scores, these responses are fed into a computer program which processes the data (FHSQ, Version 1.03). Section one assesses foot pain, foot function, footwear, and general foot health. Each domain shows a specific number of questions (4 questions with respect to pain, 4 with respect to function, 3 with respect to footwear, and 2 considering general foot health). In addition, pain and function evaluations are based on physical phenomena. Footwear assessment uses practical characteristics related to availability and shoe comfort, as well as the perception of general foot health based on patients' self-assessment of their feet status. Section one has demonstrated a high degree of validity in terms of content, criteria, and construction (Cronbach $\alpha=0.89-0.95$ ) and high retest reliability (intra-class correlation coefficient $=0.74-0.92) .{ }^{13}$ Section two evaluates general health, physical activity, social capacity, and vigor, largely adapted from the Medical Outcomes Study 36-Item Short-Form Health Survey, ${ }^{13}$ which has been demonstrated to be valid. ${ }^{19}$ Section three focuses on sociodemographic data such as patients' age, medical features, study level (incomplete primary, complete primary, secondary, degree, and superior degree), professional activity (student, freelance, employed, unemployed, and retired), civil status (single, divorced, widowed, couple, and married), and medical record. In addition, the Spanish FHSQ version provides adequate psychometric properties. ${ }^{20}$

\section{Calculation of sample size}

We established a minimum difference in FHSQ score of $\geq 21$ as being clinically relevant among the group under study. Also, the SD on the FHSQ for such a group is $\approx 29 .{ }^{2,20}$ Hence, for a bilateral hypothesis, an $\alpha$ risk of $5 \%$, and a statistical power of $80 \%, \geq 94$ cases may be studied in a sample of patients with PF.

\section{Statistical analyses}

Demographic characteristics (age, height, weight, BMI) and independent variables are described as the mean and SD as well as maximum and minimum values, and were compared between males and females.

All variables were examined for normality of distribution using the Kolmogorov-Smirnov test, and data were considered to have a normal distribution if $P>0.05$. Independent Student's $t$-tests were undertaken to ascertain if differences were significant when showing a normal distribution. Measurements that did not have a normal distribution were tested using the non-parametric Kruskal-Wallis test to examine differences between males and females. Finally, the FHSQ scores for specific foot domains (foot pain, foot function, general foot health, footwear) and for four domains of general wellbeing (overall health, physical function, social capacity, vigor) were analyzed according to sex.

The FHSQ v1.03 was used to obtain QoL scores related to foot health. In all analyses, statistical significance was established at $P<0.05$ with a $\mathrm{CI}$ of $95 \%$. All analyses were carried out using SPSS v19.0 (IBM Corporation, Armonk, NY, USA).

\section{Results}

One hundred patients aged 18-64 (mean \pm SD, $43.16 \pm$ 14.136) years completed the study. Table 1 shows the sociodemographic characteristics of the participants. A significant difference in height and weight $(P<0.05)$ was observed. Nevertheless, there were no significant differences in age, the BMI, level of education, professional activity, and civil status between males and females $(P>0.05)$.

The results of the comparison between the FHSQ scores of males and females are shown in Table 2. With regard to section one of the FHSQ, which evaluates four specific foot domains, significant differences $(P<0.05)$ were shown for foot pain and footwear. They showed a worse QoL related to foot health for females, with females having lower scores than males, but not for foot function or general foot health $(P>0.05)$. In section two, which assesses four domains of general wellbeing, significant differences $(P<0.05)$ were shown for overall health, physical function, social capacity, and vigor. This result showed a worse QoL related to general health for females, with females having lower scores than males.

\section{Discussion}

Studies have examined the QoL of patients with heel spurs. ${ }^{21,22}$ However, this is the first study to show that PF can influence the QoL of male and female patients with PF in terms of foot health and health in general, as measured by the FHSQ. The FHSQ scores in patients with PF (49\% males and 51\% 
Table I Sociodemographic and clinical characteristics of the sample population

\begin{tabular}{|c|c|c|c|c|}
\hline & $\begin{array}{l}\text { Total group mean } \pm \text { SD } \\
\text { (range), } N=100\end{array}$ & $\begin{array}{l}\text { Male mean } \pm S D \\
\text { (range), } N=49\end{array}$ & $\begin{array}{l}\text { Female mean } \pm \text { SD } \\
\text { (range), } N=5 I\end{array}$ & $P$-value \\
\hline Age (years) & $\begin{array}{l}43.16 \pm 14.136 \\
(18-64)\end{array}$ & $\begin{array}{l}42.38 \pm 14.065 \\
(18-64)\end{array}$ & $\begin{array}{l}43.90 \pm 14.305 \\
(19-64)\end{array}$ & 0.297 \\
\hline Weight (kg) & $\begin{array}{l}75.77 \pm 14.342 \\
(48-120)\end{array}$ & $\begin{array}{l}82.37 \pm 13.372 \\
(60-120)\end{array}$ & $\begin{array}{l}69.43 \pm 12.327 \\
(48-95)\end{array}$ & 0.001 \\
\hline Height (cm) & $\begin{array}{l}167.68 \pm 8.115 \\
(148-186)\end{array}$ & $\begin{array}{l}173.10 \pm 0.062 \\
(155-186)\end{array}$ & $\begin{array}{l}162.47 \pm 6.007 \\
(148-178)\end{array}$ & 0.001 \\
\hline BMI $\left(\mathrm{kg} / \mathrm{m}^{2}\right)$ & $\begin{array}{l}26.88 \pm 4.463 \\
(17.84-41.52)\end{array}$ & $\begin{array}{l}27.470 \pm 4.146 \\
(20.76-41.52)\end{array}$ & $\begin{array}{l}26.327 \pm 4.72 \mid \\
(17.84-37.33)\end{array}$ & 0.101 \\
\hline Study level & $\begin{array}{l}3.14 \pm 1.214 \\
(1-5)\end{array}$ & $\begin{array}{l}3.22 \pm 1.026 \\
(I-5)\end{array}$ & $\begin{array}{l}3.06 \pm 1.377 \\
(1-5)\end{array}$ & 0.249 \\
\hline Professional activity & $\begin{array}{l}2.68 \pm 1.246 \\
(1-5)\end{array}$ & $\begin{array}{l}2.55 \pm 1.062 \\
(1-5)\end{array}$ & $\begin{array}{l}2.80 \pm 1.400 \\
(1-5)\end{array}$ & 0.1564 \\
\hline Civil status & $\begin{array}{l}3.4 I \pm 1.82 \\
(I-5)\end{array}$ & $\begin{array}{l}3.45 \pm 1.872 \\
(1-5)\end{array}$ & $\begin{array}{l}3.37 \pm 1.778 \\
(1-5)\end{array}$ & 0.417 \\
\hline
\end{tabular}

Notes: In all the analyses, $P<0.05$ (with a $95 \% \mathrm{Cl}$ ) was considered statistically significant. $P$-values are from Kruskal-Wallis test. Study level (incomplete primary $=1$, complete primary $=2$, secondary $=3$, degree $=4$, and superior degree $=5$ ); professional activity (student $=1$, freelance $=2$, employed $=3$, unemployed $=4$, and retired $=5$ ); and civil status ( ingle $=I$, divorced $=2$, widowed $=3$, couple $=4$, and married $=5$ ) were considered.

Abbreviation: BMI, body mass index.

Table 2 Comparisons of FHSQ scores between males and females

\begin{tabular}{|c|c|c|c|c|}
\hline & $\begin{array}{l}\text { Total group mean } \pm \text { SD } \\
\text { (range), } N=100\end{array}$ & $\begin{array}{l}\text { Male mean } \pm S D \\
\text { (range), } N=49\end{array}$ & $\begin{array}{l}\text { Female mean } \pm S D \\
\text { (range), } N=5 I\end{array}$ & $P$-value \\
\hline Foot pain & $\begin{array}{l}4 \mid .4 I \pm 21.36 \\
(0-85)\end{array}$ & $\begin{array}{l}44.69 \pm 20.20 \\
(0-85)\end{array}$ & $\begin{array}{l}36.96 \pm 19.52 \\
(0-8 I)\end{array}$ & 0.036 \\
\hline Foot function & $\begin{array}{l}50.87 \pm 23.52 \\
(0-100)\end{array}$ & $\begin{array}{l}52.93 \pm 22.96 \\
(18-93)\end{array}$ & $\begin{array}{l}46.81 \pm 23.43 \\
(0-100)\end{array}$ & 0.075 \\
\hline Footwear & $\begin{array}{l}53.58 \pm 32.67 \\
(0-100)\end{array}$ & $\begin{array}{l}59.01 \pm 32.57 \\
(0-100)\end{array}$ & $\begin{array}{l}46.56 \pm 33.67 \\
(0-100)\end{array}$ & 0.018 \\
\hline General foot health & $\begin{array}{l}32.80 \pm 24.88 \\
(0-100)\end{array}$ & $\begin{array}{l}36.53 \pm 25.00 \\
(0-100)\end{array}$ & $\begin{array}{l}29.80 \pm 25.16 \\
(0-100)\end{array}$ & $0.07 I$ \\
\hline General health & $\begin{array}{l}67.70 \pm 30.54 \\
(0-100)\end{array}$ & $\begin{array}{l}74.89 \pm 29.86 \\
(0-100)\end{array}$ & $\begin{array}{l}59.60 \pm 30.32 \\
(0-100)\end{array}$ & 0.002 \\
\hline Physical activity & $\begin{array}{l}68.55 \pm 19.64 \\
(0-100)\end{array}$ & $\begin{array}{l}71.20 \pm 19.16 \\
(33-100)\end{array}$ & $\begin{array}{l}64.70 \pm 20.48 \\
(0-88)\end{array}$ & 0.033 \\
\hline Social capacity & $\begin{array}{l}69.12 \pm 30.53 \\
(0-100)\end{array}$ & $\begin{array}{l}76.02 \pm 28.16 \\
(0-100)\end{array}$ & $\begin{array}{l}62.74 \pm 31.96 \\
(0-100)\end{array}$ & 0.013 \\
\hline Vigor & $\begin{array}{l}56.87 \pm 24.36 \\
(0-100)\end{array}$ & $\begin{array}{l}64.54 \pm 23.15 \\
(12-100)\end{array}$ & $\begin{array}{l}49.87 \pm 24.38 \\
(0-100)\end{array}$ & 0.001 \\
\hline
\end{tabular}

Note: In all the analyses, $P<0.05$ (with a $95 \% \mathrm{Cl}$ ) was considered statistically significant.

Abbreviation: FHSQ, Foot Health Status Questionnaire.

females; $18-64$ years) were obtained. The range of age and sex of participants with PF was consistent with that of other reports. ${ }^{23} \mathrm{PF}$ is a generalized term for a range of osseous and soft-tissue pathologic abnormalities that affect the heel. ${ }^{24}$

The inclusion and exclusion criteria of our study were very similar to those found in a study by Ibrahim et al. ${ }^{15}$ Diagnostic imaging is not used routinely to assess PF. Therefore, use of a clinical diagnosis means that the case group is representative of a broader population of people seeking treatment for heel pain, ${ }^{2}$ and was consistent with our study sample.

With regard to sociodemographic data, similar results were observed in a study by López et al on hallux valgus (HV) which utilized the FHSQ. Considering section one of the FHSQ, the scores for foot pain, foot function, footwear, and general footwear were higher and more significant for HV than for PF. Section two showed similar results for health in general and vigor, but physical activity and social capacity were higher in HV than in PF. HV did not show lower scores than PF in the FHSQ. ${ }^{25}$

A negative correlation has been observed between pain intensity and health in general (without consideration of age or sex) in patients with PF. ${ }^{1}$ Our study showed differences with regard to sex and foot pain domain of the FHSQ. Nevertheless, our study did not assess the severity of pain intensity, despite this domain evaluating the QoL related to foot health secondary to the foot pain..$^{13,19,20}$ 
The impact of PF on FHSQ scores is difficult to compare with results of other studies on foot pain because of differences in inclusion and exclusion criteria. However, the FHSQ scores in the present study were similar to those of five other studies. A randomized controlled trial (RCT) of 135 people with $\mathrm{PF}^{26}$ an RCT of 92 people with $\mathrm{PF}^{27}$ a study of 140 people awaiting foot surgery for interdigital neuroma, ${ }^{18} \mathrm{a}$ study of 154 people with painful pes cavus ${ }^{28}$ showed similar conclusions to those of our study. In addition, symptomatic osteochondral lesions of the talus have shown a similar impact on patients' QoL to those of PF. Nevertheless, these lesions may be positively correlated with BMI and age. ${ }^{29}$

In agreement with the work of other authors, ${ }^{2}$ PF had a significant negative impact on foot-specific and general health-related QoL. The degree of negative impact did not seem to be associated with age, sex, height, or BMI. Moreover, no differences in symptoms were reported for unilateral or bilateral PF. Nevertheless, values of height and weight were higher in males than in females, though both sexes were influenced equally by PF.

The results of the present study show that females had lower FHSQ scores for the dimensions related to foot pain, foot function, footwear, and general foot health than males. Higher FHSQ scores were also recorded for males than for females with regard to general health, physical activity, social capacity, and vigor. Thus, females with PF are more likely than males to present a worse specific and general QoL related to foot health. This fact could be due to different footwear use, pain severity, health status, physical activity schedule or social characteristics between both sexes. This may be reflected considering that the sex-specific rate of $\mathrm{PF}$ consultations was shown to be higher among females $(0.21 \%)$ than males $(0.16 \%)$, with a higher demand of treatment. ${ }^{7}$ In addition, further study is necessary to explain how sex may influence the course of the different treatments proposed for PF considering these domains. ${ }^{8}$

Comparison of the impact of our results with those of other studies on PF is difficult due to differences in criteria and methodological variations. Few studies have focused on the relationship between QoL and foot health of adult PF patients using the FHSQ, with the exception of Irving et al. ${ }^{2}$

Our study had three main limitations. First, we lacked data on structural foot differences, choice of footwear, and participation in sports. Second, despite the greater weight of males, BMI was not significantly different between males and females, even though BMI is the main indicator recommended. ${ }^{17}$ Third, information on exclusion criteria during recruitment was not collected. Nevertheless, a non- randomized consecutive sampling method was used according to calculation of the sample size. Finally, despite foot pain being a specific domain of the FHSQ, ${ }^{13,19,20}$ the severity of pain intensity was not assessed.

A larger and more diverse (individuals from various countries) study cohort would have been beneficial to improve the strength of our study, and could help to identify whether there is a culture in which the association between PF and QoL does not exist, and identify the mechanisms involved. Future studies should examine the impact of other factors, such as ethnicity, geographic location, shoe-wearing, or socioeconomic status, on the QoL of PF patients. In addition, outcome measurements such as a visual analog scale for pain, American Orthopedic Foot and Ankle Society scores, and Medical Outcomes Study 36-Item Short-Form Health Survey could improve the evaluation of patients. ${ }^{29,30}$

\section{Conclusion}

Females showed a worse health-related QoL for foot pain, foot function, footwear, and general foot health than males. A better health-related QoL was also shown for males than for females with regard to general health, physical activity, social capacity, and vigor. Therefore, we encourage researchers and clinicians to pay special attention regarding heel health prevention and PF patients' education of these domains, especially in the female sex.

\section{Acknowledgment}

We would like to thank the patients and medical staff from the Clinic of Podiatric Medicine and Surgery, University of Extremadura, Plasencia, Spain.

\section{Author contributions}

All authors contributed to the concept, design, analyses, interpretation of data, drafting and revising the manuscript critically for important intellectual content.

\section{Disclosure}

The authors report no conflicts of interest in this work.

\section{References}

1. Fernández-Lao C, Galiano-Castillo N, Cantarero-Villanueva I, et al. Analysis of pressure pain hypersensitivity, ultrasound image, and quality of life in patients with chronic plantar pain: a preliminary study. Pain Med. 2016;17(8):1530-1541.

2. Irving DB, Cook JL, Young MA, Menz HB. Impact of chronic plantar heel pain on health-related quality of life. J Am Podiatr Med Assoc. 2008;98(4):283-289.

3. Tu P, Bytomski JR. Diagnosis of heel pain. Am Fam Physician. 2011;84(8):909-916. 
4. Radwan A, Wyland M, Applequist L, et al. Ultrasonography, an effective tool in diagnosing plantar fasciitis: a systematic review of diagnostic trials. Int J Sports Phys Ther. 2016;11(5):663-671.

5. Goff JD, Crawford R. Diagnosis and treatment of plantar fasciitis. $\mathrm{Am}$ Fam Physician. 2011;84(6):676-82.

6. Shashua A, Flechter S, Avidan L, et al. The effect of additional ankle and midfoot mobilizations on plantar fasciitis: a randomized controlled trial. J Orthop Sport Phys Ther. 2015;45(4):265-272.

7. Pollack A, Britt H. Plantar fasciitis in Australian general practice. Aust Fam Physician. 2015;44(3):90-91.

8. Landorf KB. Plantar heel pain and plantar fasciitis. BMJ Clin Evid. 2015;2015. pii: 1111 .

9. Moustafa AM, Hassanein E, Foti C. Objective assessment of corticosteroid effect in plantar fasciitis: additional utility of ultrasound. Muscles Ligaments Tendons J. 2015;5(4):289-296.

10. Agyekum EK, Ma K. Heel pain: A systematic review. Chin JTraumatol. 2015;18(3):164-169.

11. Lemont H, Ammirati KM, Usen N. Plantar fasciitis: a degenerative process (fasciosis) without inflammation. J Am Podiatr Med Assoc. 2003;93(3):234-237.

12. Phillips A, McClinton S. Gait deviations associated with plantar heel pain: a systematic review. Clin Biomech (Bristol, Avon). 2017;42:55-64.

13. Bennett PJ, Patterson C, Wearing S, Baglioni T. Development and validation of a questionnaire designed to measure foot-health status. J Am Podiatr Med Assoc. 1998;88(9):419-428.

14. von Elm E, Altman DG, Egger M, et al. The Strengthening the Reporting of Observational Studies in Epidemiology (STROBE) statement: guidelines for reporting observational studies. Lancet. 2007;370(9596):1453-1457.

15. Ibrahim MI, Donatelli RA, Schmitz C, Hellman MA, Buxbaum F. Chronic plantar fasciitis treated with two sessions of radial extracorporeal shock wave therapy. Foot Ankle Int. 2010;31(5):391-397.

16. McMillan AM, Landorf KB, Barrett JT, Menz HB, Bird AR. Diagnostic imaging for chronic plantar heel pain: a systematic review and metaanalysis. J Foot Ankle Res. 2009;2(1):32.

17. Garrow JS, Webster J. Quetelet's index (W/H2) as a measure of fatness. Int J Obes. 1985;9(2):147-153.

18. Bennett PJ, Patterson C, Dunne MP. Health-related quality of life following podiatric surgery. JAm Podiatr Med Assoc. 2001;91(4):164-173.
19. Landorf KB, Radford JA. Minimal important difference: values for the Foot Health Status Questionnaire, Foot Function Index and Visual Analogue Scale. Foot. 2008;18(1):15-19.

20. Cuesta-Vargas A, Bennett P, Jimenez-Cebrian AM, LabajosManzanares MT. The psychometric properties of the Spanish version of the Foot Health Status Questionnaire. Qual Life Res. 2013;22(7): 1739-1743.

21. Prokein B, Holtmann H, Hautmann MG, et al. Radiotherapy of painful heel spur with two fractionation regimens: results of a randomized multicenter trial after 48 weeks' follow-up. Strahlenther Onkol. 2017;193(6):483-490.

22. Niewald M, Seegenschmiedt MH, Micke O, et al. Randomized, multicenter trial on the effect of radiation therapy on plantar fasciitis (painful heel spur) comparing a standard dose with a very low dose: mature results after 12 months' follow-up. Int J Radiat Oncol Biol Phys. 2012;84(4):e455-462

23. Lapidus PW, Guidotti FP. Painful heel: report of 323 patients with 364 painful heels. Clin Orthop Relat Res. 1965;39:178-186.

24. Narváez JA, Narváez J, Ortega R, et al. Painful heel: MR imaging findings. Radiographics. 2000;20(2):333-352.

25. López D, Callejo González L, Losa Iglesias ME, et al. Quality of life impact related to foot health in a sample of older people with hallux valgus. Aging Dis. 2016;7(1):45-52.

26. Landorf KB, Keenan AM, Herbert RD. Effectiveness of foot orthoses to treat plantar fasciitis: a randomized trial. Arch Intern Med. 2006;166(12):1305-1310.

27. Radford JA, Landorf KB, Buchbinder R, Cook C. Effectiveness of low-Dye taping for the short-term treatment of plantar heel pain: a randomised trial. BMC Musculoskelet Disord. 2006;7:64

28. Burns J, Crosbie J, Ouvrier R, Hunt A. Effective orthotic therapy for the painful cavus foot: a randomized controlled trial. J Am Podiatr Med Assoc. 2006;96(3):205-211.

29. D’Ambrosi R, Maccario C, Serra N, Ursino C, Usuelli FG. Relationship between symptomatic osteochondral lesions of the talus and quality of life, body mass index, age, size and anatomic location. Foot Ankle Surg. Epub 2017 Apr 23.

30. Theodore GH, Buch M, Amendola A, et al. Extracorporeal shock wave therapy for the treatment of plantar fasciitis. Foot Ankle Int. 2004;25(5):290-297.
Journal of Pain Research

\section{Publish your work in this journal}

The Journal of Pain Research is an international, peer reviewed, open access, online journal that welcomes laboratory and clinical findings in the fields of pain research and the prevention and management of pain. Original research, reviews, symposium reports, hypothesis formation and commentaries are all considered for publication.

\section{Dovepress}

The manuscript management system is completely online and includes a very quick and fair peer-review system, which is all easy to use. Visit http://www.dovepress.com/testimonials.php to read real quotes from published authors. 